coronary infusion of a $\beta_{2}$-receptor agonist: a human in vivo study. Circulation. 99:2402-2407.

16. Rona, G., Chappel, G., Balazs, T., and Gaudry, R. 1959. An infarct-like myocardial lesion and other toxic manifestations produced by isoproterenol in the rat. Arch. Pathol. 67:443-455.

17. Beznak, M., and Hacker, P. 1964. Hemodynamics during the chronic stage of myocardial damage caused by isoproterenol. Can. J. Physiol. Pharmacol. 42:269-274.

18. Woodiwiss, A.J., et al. 2001. Reduction in myocardial collagen cross-linking parallels left ventricular dilatation in rat models of systolic chamber dysfunction. Circulation. 103:155-160

19. Zhu, W.Z., et al. 2003. Linkage of $\beta_{1}$-adrenergic stimulation to apoptotic heart cell death through protein kinase A-independent activation of $\mathrm{Ca}^{2+}$ calmodulin kinase II. J. Clin. Invest. 111:617-625. doi:10.1172/JCI200316326.

20. Engelhardt, S., Hein, L., Wiesmann, F., and Lohse, M. 1999. Progressive hypertrophy and heart failure in $\beta_{1}$-adrenergic receptor transgenic mice. Proc. Natl. Acad. Sci. U. S. A. 96:7059-7064.

21. Liggett, S.B., et al. 2000. Early and delayed consequences of $\beta_{2}$-adrenergic receptor overexpression in mouse hearts: critical role for expression level. Circulation. 101:1707-1714.

22. Antos, C.L., et al. 2001. Dilated cardiomyopathy and sudden death resulting from constitutive activation of protein kinase A. Circ. Res. 89:997-1004.

23. Vatner, S.F., Vatner, D.E., and Homcy, C.J. 2000. $\beta$-adrenergic receptor signaling: an acute compensatory adjustment - inappropriate for the chronic stress of heart failure? Insights from $\mathrm{G}_{\mathrm{s}} \alpha$ overexpression and other genetically engineered animal models. Circ. Res. 86:502-506.

25. Rector, T.S., and Cohn, J.N. 1994. Prognosis in congestive heart failure. Annu. Rev. Med. 45:341-350

26. Ungerer, M., Bohm, M., Elce, J.S., Erdmann, E., and Lohse, M.J. 1993. Altered expression of $\beta$ adrenergic receptor kinase and $\beta_{1}$-adrenergic receptors in the failing human heart. Circulation. 87:454-463.

27. Nienaber, J.J., et al. 2003. Inhibition of receptorlocalized PI3K preserves cardiac $\beta$-adrenergic receptor function and ameliorates pressure overload heart failure. J. Clin. Invest. 112:1067-1079. doi:10.1172/ JCI200318213.

28. Freedman, N.J., et al. 1995. Phosphorylation and desensitization of the human $\beta_{1}$-adrenergic receptor: involvement of $\mathrm{G}$ protein-coupled receptor kinases and cAMP-dependent protein kinase. J. Biol. Chem. 270:17953-17961.

29. Rockman, H.A., et al. 1998. Control of myocardial contractile function by the level of $\beta$-adrenergic receptor kinase 1 in gene-targeted mice. J. Biol. Chem. 273:18180-18184.

30. Cho, M.C., et al. 1999. Defective $\beta$-adrenergic receptor signaling precedes the development of dilated cardiomyopathy in transgenic mice with calsequestrin overexpression. J. Biol. Chem. 274:22251-22256.

31. Rockman, H.A., et al. 1998. Expression of a $\beta$-adrenergic receptor kinase 1 inhibitor prevents the development of myocardial failure in gene-targeted mice. Proc. Natl. Acad. Sci. U. S. A. 95:7000-7005.

32. Harding, V.B., Jones, L.R., Lefkowitz, R.J., Koch, W.J., and Rockman, H.A. 2001. Cardiac $\beta A R K 1$ inhibition prolongs survival and augments beta blocker therapy in a mouse model of severe heart failure. Proc. Natl. Acad. Sci. U. S. A. 98:5809-5814.

33. Pitcher, J.A., Freedman, N.J., and Lefkowitz, R.J. 1998. G protein-coupled receptor kinases. Annu. Rev. Biochem. 67:653-692.

34. Peppel, K., et al. 2000. Overexpression of G proteincoupled receptor kinase- 2 in smooth muscle cells attenuates mitogenic signaling via $G$ protein-coupled and platelet-derived growth factor receptors. Circulation. 102:793-799.

35. Bristow, M.R. 2000. $\beta$-adrenergic receptor blockade in chronic heart failure. Circulation. 101:558-569.

36. Metra, M., et al. 2002. Beta-blocker therapy influenc- es the hemodynamic response to inotropic agents in patients with heart failure: a randomized comparison of dobutamine and enoximone before and after chronic treatment with metoprolol or carvedilol. J. Am. Coll. Cardiol. 40:1248-1258.

37. Sabbah, H.N., et al. 2000. Chronic therapy with metoprolol attenuates cardiomyocyte apoptosis in dogs with heart failure. J. Am. Coll. Cardiol. 36:1698-1705.

38. Gaussin, V., et al. 2003. Common genomic response in different mouse models of $\beta$-adrenergic-induced cardiomyopathy. Circulation. 108:2926-2933.

39. Lowes, B.D., et al. 2002. Myocardial gene expression in dilated cardiomyopathy treated with beta-blocking agents. N. Engl. J. Med. 346:1357-1365.

40. Reiken, S., et al. 2001. $\beta$-adrenergic receptor blockers restore cardiac calcium release channel (ryanodine receptor) structure and function in heart failure. Circulation. 104:2843-2848.

41. Reiken, S., et al. 2003. $\beta$-blockers restore calcium release channel function and improve cardiac muscle performance in human heart failure. Circulation. 107:2459-2466.

42. Ping, P., et al. 1995. Reduced $\beta$-adrenergic receptor activation decreases G-protein expression and $\beta$-adrenergic receptor kinase activity in porcine heart. J. Clin. Invest. 95:1271-1280.

43. Iaccarino, G., Tomhave, E.D., Lefkowitz, R.J., and Koch, W.J. 1998. Reciprocal in vivo regulation of myocardial G protein-coupled receptor kinase expression by $\beta$-adrenergic receptor stimulation and blockade. Circulation. 98:1783-1789.

44. Beyer, M.E., Nerz, S., Kazmaier, S., and Hoffmeister, H.M. 1995. Effect of endothelin-1 and its combination with adenosine on myocardial contractility and myocardial energy metabolism in vivo. J. Mol. Cell. Cardiol. 27:1989-1997.

45. Mobini, R., et al. 2003. Hemodynamic improvement and removal of autoantibodies against $\beta_{1}$-adrenergic receptor by immunoadsorption therapy in dilated cardiomyopathy. J. Autoimmun. 20:345-350.

\title{
Dissecting the functional role of different isoforms of the L-type $\mathrm{Ca}^{2+}$ channel
}

\author{
Emmanuel Bourinet, Matteo E. Mangoni, and Joël Nargeot
}

Département de Physiologie, Laboratoire de Génomique Fonctionnelle, Centre National de la Recherche Scientifique Unité Propre de Recherche 2580, Montpellier, France.

\begin{abstract}
There currently exist a great number of different mouse lines in which the activity of a particular gene of interest has been inactivated or enhanced. However, it is also possible to insert specific mutations in a gene so that the pharmacological sensitivity of the gene product is altered. An example of such an approach shows how the abolition of the sensitivity of an L-type $\mathrm{Ca}^{2+}$ channel isoform to dihydropyridines allows the investigation of the physiological role of these channels in different tissues (see the related article beginning on page 1430).
\end{abstract}

Nonstandard abbreviations used: dihydropyridine (DHP); L-type $\mathrm{Ca}^{2+}$ channel (LTCC).

Conflict of interest: The authors have declared that no conflict of interest exists.

Citation for this article:

J. Clin. Invest. 113:1382-1384 (2004).

doi:10.1172/JCI200421815

\section{The LTCC family}

L-type $\mathrm{Ca}^{2+}$ channels (LTCCs) are formed by different pore-forming $\alpha 1$ subunit isoforms named $\mathrm{Ca}_{v} 1.1, \mathrm{Ca}_{v} 1.2, \mathrm{Ca}_{v} 1.3$, and $\mathrm{Ca}_{v} 1.4$ associated to auxiliary subunits $(\alpha 2-\delta, \beta$, and $\gamma)(1)$. The common pharmacological hallmark of all native and recom- binant LTCCs is their sensitivity to dihydropyridines (DHPs). However, the small differences among the LTCC $\alpha 1$ isoforms in their affinity for DHPs (agonists and antagonists) have limited the study of the functional role of these channels in various tissues, including the cardiovascular system, the brain, and the endocrine glands.

In this issue of the JCI, Sinnegger-Brauns and coworkers report that they have developed a new mouse model resulting from a knock-in mutation of the Cav 1.2 voltage-dependent LTCC subunit which abolishes the sensitivity of the channel to DHP (referred to herein as the $\mathrm{Ca}_{V} 1.2 \mathrm{DHP}^{-/-}$ mouse) (see Figure 1) (2). Since $\mathrm{Ca}_{v} 1.2$ is 

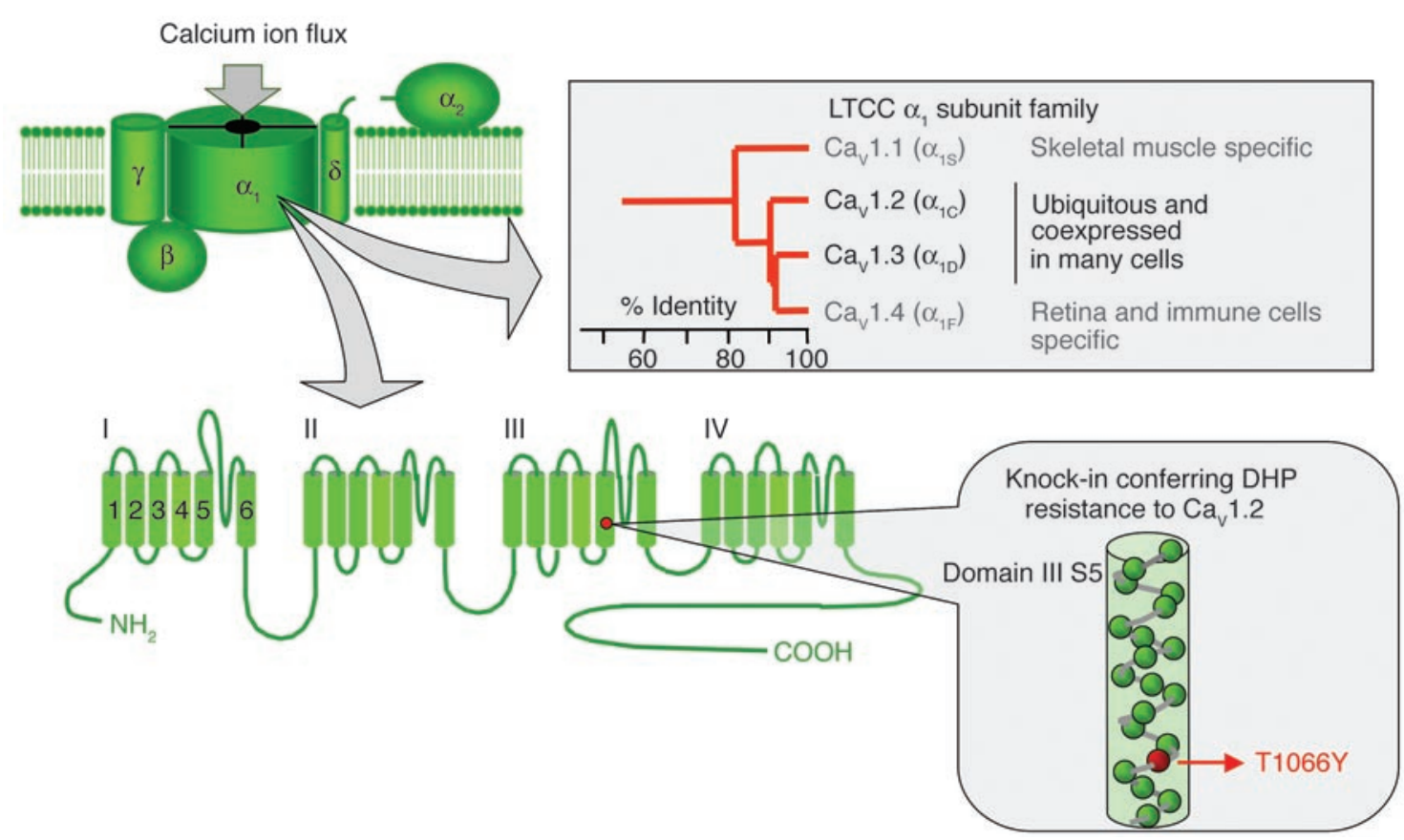

Figure 1

LTCCs are multimeric complexes of subunits formed by an $\alpha 1$ pore-forming protein associated to three auxiliary subunits ( $\alpha 2-\delta, \beta$, and $\gamma$ ). Four genes encode the pore-forming subunit $\left(\mathrm{Ca}_{v} 1.1-\mathrm{Ca}_{v} 1.4\right)$. The primary structure, $\alpha 1$, is represented in the figure showing the four domains composed of six transmembrane segments. Schematic representation of the knock-in mutation in the Cav1.2 gene (Thr1066 to Tyr) realized by SinneggerBrauns and coworkers in this issue of the $\mathrm{JCl}(2)$ to discriminate in vivo the contributions of Cav1.2 and Cav1.3 to various physiological functions.

almost ubiquitously expressed in excitable cells, the model provides a very elegant and promising approach for investigating the physiological role of the other DHP-sensitive LTCC isoforms $\left(\mathrm{Ca}_{v} 1.1, \mathrm{Ca}_{v} 1.3\right.$, and $\left.\mathrm{Ca}_{v} 1.4\right)$. This model is particularly useful for the exploration of the function of $\mathrm{Ca}_{v} 1.3$ channels, which are coexpressed with $\mathrm{Ca}_{v} 1.2$ but at a much lower level in most cell types investigated so far. The $\mathrm{Ca}_{\mathrm{v}} 1.1$ subunit is responsible for excitation-contraction coupling in skeletal muscle (3), while $\mathrm{Ca}_{v} 1.4$ expression appears to be restricted to the retina and $\mathrm{T}$ lymphocytes (4-6). In contrast to the tissue-specific expression of $\mathrm{Ca}_{v} 1.1$ and $\mathrm{Ca}_{v} 1.4$, both $\mathrm{Ca}_{v} 1.2$ and $\mathrm{Ca}_{\mathrm{v}} 1.3$ are widely expressed and distributed in the brain, the cardiovascular system, and neuroendocrine cells.

\section{$\mathrm{Ca}_{\mathrm{v}} 1.2$ versus $\mathrm{Ca}_{\mathrm{v}} \mathbf{1 . 3}$ in insulin secretion}

Using the $\mathrm{Ca}_{V} 1.2 \mathrm{DHP}^{-/-}$mice that exhibit a normal phenotype in spite of their DHPinsensitive $\mathrm{Ca}_{v} 1.2$ channels, the authors have been able to differentiate, both in vivo and in vitro, the roles of the $\mathrm{Ca}_{\mathrm{v}} 1.2$ and $\mathrm{Ca}_{v} 1.3$ channels in insulin secretion, cardiac performance, and mood behavior (2). In particular, the finding that insulin secretion in these mice was completely insensitive to DHP agonists and antagonists provides strong evidence in the long-standing debate about the insulin secretagogue role of the $\mathrm{Ca}_{v} 1.2$ and $\mathrm{Ca}_{v} 1.3$ channels. Opposite conclusions about the importance of the $\mathrm{Ca}_{v} 1.3$ LTCC in this secretion process have been drawn by two previous studies using different mouse strains lacking the $\mathrm{Ca}_{v} 1.3$ LTCC $(7,8)$ and a $\beta$-cell-specific knockout of the $\mathrm{Ca}_{\mathrm{v}}$ 1.2 LTCC (9). The complete resistance of the insulin secretory process to DHPs in the $\mathrm{Ca}_{\mathrm{V}} 1.2 \mathrm{DHP}^{-/-}$mice strongly supports the minor role of $\mathrm{Ca}_{v} 1.3$ in this process.

\section{LTCC isoforms in mood behavior}

Another important aspect of the study concerns the role of the $\mathrm{Ca}_{v} 1.3$ LTCC in integrated neuronal functions. While the expression of the $\mathrm{Ca}_{\mathrm{v}} 1.2$ LTCC isoform accounts for about $80 \%$ of the overall DHP-binding sites in the brain, the remaining $20 \%$ of binding can be attributed to $\mathrm{Ca}_{v} 1.3$ LTCCs, and little was known about the function of these channels. Indeed, DHP agonists such as BayK8644 cannot be used in vivo because of potent neurotoxic effects mediated by $\mathrm{Ca}_{v} 1.2$ channels. Abolition of the sensitivity of the $\mathrm{Ca}_{v} 1.2$ channel to DHPs allowed unmasking of a depression-like behavioral effect mediated by $\mathrm{Ca}_{v} 1.3$ channels (2). From a molecular point of view, these effects may rely on the recently identified specific interactions of the $\mathrm{Ca}_{V} 1.3$ channel with synaptic proteins (10), with possible consequences related to the control of neurotransmitter release classically implicated in depression (as shown by SinneggerBrauns et al. in the case of dopamine). Therefore, an attractive prospective application of these findings is in the development of new classes of antidepressant drugs that act selectively on $\mathrm{Ca}_{v} 1.3$ channels.

\section{Relevance of the Cav1.2DHP-/- mouse in the study of heart physiology}

The Cav1.2DHP-/- mouse model can also help to reveal the functional role of LTCCs in the physiology of the heart. It is widely accepted that the $\mathrm{Ca}_{v} 1.2$ subunit constitutes the most abundant LTCC subunit in the heart, where it plays an important role in excitation-contraction coupling in the working myocardium. In addition, a growing body of evidence indicates that the functional roles of $\mathrm{Ca}_{\mathrm{v}} 1.2$ and $\mathrm{Ca}_{v} 1.3$ channels are distinct in the heart, with $\mathrm{Ca}_{\mathrm{v}} 1.3$ channels playing a major role in pacemaker activity. Indeed, the fact that mice in which the gene encoding the $\mathrm{Ca}_{v} 1.3$ subunit has been inactivated show prominent dysfunctions in pacemaker activity in 
vivo and in vitro demonstrates that $\mathrm{Ca}_{v} 1.3$ channels constitute the major component of the L-type current in pacemaker cells (8, 11, 12). Experimental results presented by Sinnegger-Brauns and coworkers clearly support this view (2). More generally, the use of engineered mice such as $\mathrm{Ca}_{V} 1.2 \mathrm{DHP}^{-/-}$mice will be of particular interest to further assess the contribution of the different ionic currents underlying diastolic depolarization in sinoatrial pacemaker cells. Automaticity in cardiac pacemaker cells is due to the slow diastolic depolarization phase, which drives the membrane voltage from the end of the action potential to the threshold of the following action potential. Both native and recombinant $\mathrm{Ca}_{v} 1.3$ channels exhibit more negative threshold for activation and slower inactivation kinetics than $\mathrm{Ca}_{v} 1.2$ channels. In other words, the low threshold of $\mathrm{Ca}_{v} 1.3$ current is consistent with a major role during diastolic depolarization (12), while a sustained calcium influx is required for the contractility of heart cells.

In conclusion, the originality of this model offers stimulating prospects for dissecting the physiological roles of calcium channels in various tissues (2). This genetic "reverse" pharmacology in vivo is likely to be applied in the future to other channels and receptor families sharing a similar pharmacology.

Address correspondence to: Emmanuel Bourinet, Département de Physiologie, Laboratoire de Génomique Fonctionnelle, Centre National de la Recherche Scientifique Unité Propre de Recherche 2580, 141, rue de la Cardonille, 34396 Montpellier Cedex 05, France. Phone: 33-499-61-99-36; Fax: 33-499-61-99-01; E-mail: Emmanuel. Bourinet@igh.cnrs.fr.

1. Striessnig, J. 1999. Pharmacology, structure and function of cardiac L-type $\mathrm{Ca}(2+)$ channels. Cell. Physiol. Biochem. 9:242-269.

2. Sinnegger-Brauns, M.J., et al. 2004. Isoform-specific regulation of mood behavior and pancreatic $\beta$ cell and cardiovascular function by L-type $\mathrm{Ca}^{2+}$ channels. J. Clin. Invest. 113:1430-1439. doi:10.1172/JCI200420208.

3. Tanabe, T., Beam, K.G., Powell, J.A., and Numa, S. 1988. Restoration of excitation-contraction coupling and slow calcium current in dysgenic muscle by dihydropyridine receptor complementary DNA. Nature. 336:134-139.
4. McRory, J.E., et al. 2004. The CACNA1F gene encodes an L-type calcium channel with unique biophysical properties and tissue distribution. J. Neurosci. 24:1707-1718.

5. Kotturi, M.F., Carlow, D.A., Lee, J.C., Ziltener, H.J., and Jefferies, W.A. 2003. Identification and functional characterization of voltage-dependent calcium channels in T lymphocytes. J. Biol. Chem. 278:46949-46960.

6. Koschak, A., et al. 2003. Cav1.4alpha1 subunits can form slowly inactivating dihydropyridine-sensitive L-type $\mathrm{Ca} 2+$ channels lacking $\mathrm{Ca} 2+$-dependent inactivation. J. Neurosci. 23:6041-6049.

7. Namkung, Y., et al. 2001. Requirement for the L-type $\mathrm{Ca}(2+)$ channel alpha(1D) subunit in postnatal pancreatic beta cell generation. J. Clin. Invest. 108:1015-1022. doi:10.1172/JCI200113310.

8. Platzer, J., et al. 2000. Congenital deafness and sinoatrial node dysfunction in mice lacking class D L-type Ca2+ channels. Cell. 102:89-97.

9. Schulla, V., et al. 2003. Impaired insulin secretion and glucose tolerance in beta cell-selective $\mathrm{Ca}(\mathrm{v}) 1.2$ Ca2+ channel null mice. EMBO J. 22:3844-3854.

10. Hibino, H., et al. 2002. RIM binding proteins (RBPs) couple Rab3-interacting molecules (RIMs) to voltage-gated $\mathrm{Ca}(2+)$ channels. Neuron. 34:411-423.

11. Zhang, Z., et al. 2002. Functional roles of $\mathrm{Ca}(\mathrm{v}) 1.3$ (alpha(1D)) calcium channel in sinoatrial nodes: insight gained using gene-targeted null mutant mice. Circ. Res. 90:981-987.

12. Mangoni, M.E., et al. 2003. Functional role of L-type Cav1.3 Ca2+ channels in cardiac pacemaker activity. Proc. Natl. Acad. Sci. U. S. A. 100:5543-5548.

\title{
Amyloid at the cutting edge: activation of $\alpha$-secretase prevents amyloidogenesis in an Alzheimer disease mouse model
}

\author{
Stefan F. Lichtenthaler and Christian Haass
}

Adolf-Butenandt-Institut, Laboratory for Alzheimer's and Parkinson's Disease Research, Ludwig-Maximilians-Universität, Munich, Germany.

\begin{abstract}
The amyloid $\beta$-peptide (A $\beta$ peptide) is assumed to play a crucial and early role in the pathogenesis of Alzheimer disease. Thus, strategies for a pharmacotherapy aim at reducing $A \beta$ peptide generation, which proteolytically derives from the amyloid precursor protein (APP). The main targets so far have been $\beta$ - and $\gamma$-secretase, the two proteases that cleave APP at the $\mathrm{N}$ - and $\mathrm{C}$-terminus of the $A \beta$ peptide and are thus directly responsible for $A \beta$ peptide generation. A different strategy, namely the activation of $\alpha$-secretase, has barely been investigated for its therapeutic potential. $\alpha$-Secretase cleaves within the $A \beta$ peptide domain and thus precludes $A \beta$ peptide generation. Now, new results demonstrate that activation of $\alpha$-secretase indeed reduces $A \beta$ peptide generation and toxicity in vivo (see the related article beginning on page 1456).
\end{abstract}

\footnotetext{
Nonstandard abbreviations used: a disintegrin and metalloprotease (ADAM); Alzheimer disease (AD); amyloid $\beta$-peptide (A $\beta$ peptide); amyloid precursor protein (APP).

Conflict of interest: The authors have declared that no conflict of interest exists.

Citation for this article:

J. Clin. Invest. 113:1384-1387 (2004).

doi:10.1172/JCI200421746.
}

Numerous laboratories are currently investigating $\beta$ - and $\gamma$-secretase, the two amyloidogenic proteases that cleave the A $\beta$-peptide out of the amyloid precursor protein (APP). The reason is obvious. If we prevent these proteases from working, we will stop the progression of Alzheimer disease (AD). However, a rather old and almost forgotten idea, namely the activation of $\alpha$-secretase, which cuts the amyloid $\beta$-peptide ( $\mathrm{A} \beta$ peptide) into two nonamyloidogenic pieces, has now been reinvestigated. Compelling evidence that this strategy may work is now presented in a study by researchers in Germany and Belgium led by Falk Fahrenholz at the University of Mainz (1).

$\mathrm{AD}$ is the most prevalent neurodegenerative disease, affecting about 20 million people worldwide (for an overview see ref. 2). The amyloid hypothesis of $\mathrm{AD}$, which is now widely accepted, describes the pathogenesis of this disease as a cascade of several steps, from the initial generation of the $A \beta$ peptide to cognitive impairment and neuronal loss (for overviews see refs. 3, 4). Whereas drugs are currently available that may slightly 